\section{DE PROPUESTAS TEÓRICAS A LA PRÁCTICA ARQUITECTÓNICA. MIGUEL FISAC Y SU PRIMERA OBRA MODERNA}

FROM THEORY TO ARCHITECTURAL PRACTICE. THE FIRST MODERN BUILDING OF MIGUEL FISAC

VON DER AKADEMISCHEN LEHRE ZU DER ARCHITEKTONISCHEN PRAXIS: DAS ERSTE MODERNE WERK VON MIGUEL FISAC

RESUMEN: Los años cincuenta fueron fructíferos para el desarrollo de la arquitectura moderna en España. Muchos arquitectos afianzaron sus lenguajes buscando la introducción de elementos novedosos. Algunas de las construcciones más enigmáticas del momento fueron el Gobierno Civil de Tarragona y el Pabellón de los Hexágonos en la Exposición de Bruselas de 1958, edificios representativos del Estado Español que se construyeron con una estética marcadamente moderna que nos indicaba que algo había ocurrido en la política arquitectónica del gobierno franquista. En todo este proceso de modernización destacó la figura de Miguel Fisac, que tuvo un papel protagonista tanto en su faceta teórica como por su singular obra.

PALABRAS ClAVE: Miguel Fisac; franquismo; movimiento moderno; política artística; siglo XX.
ABSTRACT: The fifties were important in Spain for the creation of a modern architecture. The architects, who began working in previous years, created his artistic languages inspired in modern styles. We find examples in Tarragona's Civil Government Building and the National Pavilion in the 1958 Brussels' Exhibition. Both are a representative Spanish State buildings in a modern style inside and out of Spain limits. This situation shows us that something happened in the artistic politics of Franco 's government. Fisac was very important in this process: the modernization of the Spanish architecture.

KEYWORDS: Miguel Fisac; Franco's Government; modernist movement; Artistic politics; 20th century.
ZUSAMMENFASSUN: Die fünfziger Jahren gelten als eine sehr fruchtbringende Epoche für die Entwicklung der modernen Architektur in Spanien. Viele Architekten bereicherten ihre Kunstsprache durch die Einführung moderner Bauelemente. Als Beispiele der Baukunst der Periode können E Gobierno Civil de Tarragona und E Pabellón de los Hexágonos bei der Weltausstellung 1958 in Brüssel gennant werden. Beide stehen als repräsentative Gebäude stellvertretend für die moderne Baukunst des spanischen Staates und weisen auf die neue Baupolitik der Regierung Franco. Miguel Fisac wird oft als Hauptfigur diseses Modernisierungsprozesses erwähnt.

SCHLÜSSELWÖRTER: Miguel Fisac; Franquismus, moderne Baukunst; Politik der Kunst; XX Jahrhundert.
DÍAZ DEL CAMPO MARTÍN MANTERO, Ramón Vicente

Universidad de Castilla-La Mancha (UCLM)

Departamento de Historia del Arte Avda. Camilo José Cela s/n 13071 Ciudad Real

RamonVicente.Diaz@uclm.es

ORCID ID: 0000-0003-2181-839x

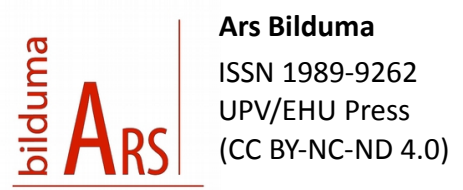

https://doi.org/10.1387/ars-bilduma.16518 BIBLID [(2018), 8; 201-217]

Recep.: 21/06/2016 Acept.: 13/09/2016 
El Régimen de Francisco Franco intentó controlar diversos aspectos de la vida de los españoles, imponiendo una serie de valores que en general se pueden calificar como conservadores y tradicionales. La arquitectura fue uno de los ámbitos donde el Nuevo Estado intentó, a través de distintas iniciativas e instituciones, generar un estilo acorde con el modo de vida que intentó imponer. Pero el bando vencedor no fue homogéneo y coexistían varios sectores con diferencias de pensamiento. Entre los grupos que más pugnaban por influir en la sociedad española destacaban Falange y la Iglesia Católica. Por este y otros motivos no existió una política arquitectónica unitaria y se desarrollaron distintas vertientes con diferentes resultados. El gobierno español tuvo que cambiar el rumbo político después de la Segunda Guerra Mundial, su supervivencia se sustentó en la integración en el nuevo panorama político internacional. En este escenario propiciado por el desbloqueo diplomático se incentivó el reencuentro con la vanguardia, o dicho de otro modo, se potencio la recepción de la modernidad en la arquitectura española bajo el mecenazgo del franquismo ${ }^{1}$. Miguel Fisac fue uno de los protagonistas de la renovación de la arquitectura española. En el presente texto pretendemos analizar su figura a través de una doble vertiente. Por un lado, se analiza su papel como autor de algunos de los hitos significativos dentro del debate teórico reflejado en las revistas de arquitectura, mientras que en una segunda parte se indaga cómo se reflejaron esas ideas en una de sus obras más relevantes: el Instituto Laboral de Daimiel.

1 PÉREZ ESCOLANO, V.: "La arquitectura española del segundo franquismo y el Boletín de la Dirección General de Arquitectura, 1946-1957", Ra: revista de Arquitectura, no 16, 2014, p. 28.

\section{FISAC Y EL DEBATE SOBRE EL ESTADO DE LA ARQUITECTURA ESPAÑOLA}

Al final de los años cuarenta, período en el que instituciones y organismos difundieron y promovieron una arquitectura "de corte imperial" ${ }^{2}$ y de "revival tradicionales" ${ }^{3}$, desde varios sectores surgió una necesidad de debate y algunas entidades oficiales tuvieron la habilidad de plantear en público el problema. No solo no se pusieron impedimentos, todo lo contrario, se apoyó y se incentivó. Un momento de cambio que afectó a múltiples ámbitos del panorama artístico español, donde se trató de promover un nuevo arte de corte internacional pero vinculado a la tradición española ${ }^{4}$. En este contexto se inició un periodo fructífero para el desarrollo de una segunda modernidad en la arquitectura. Se utilizaron las revistas profesionales como medio ideal para la difusión de nuevas ideas y propuestas. Estas publicaciones, en los primeros años de la década eran pocas y con unos planteamientos muy parecidos, paulatinamente se modernizaron y apareciendo otras nuevas, convirtiéndose en un elemento clave en el proceso de renovación del escenario arquitectónico. En el proceso de recomposición que vive la arquitectura española destacó Miguel Fisac, siendo el artífice de diversos edificios cargados de una rabiosa modernidad y al mismo tiempo autor de varios textos significativos en el debate generado en diversas publicaciones.

2 RÁBANOS FACl, C.: "Estética de la representación en los regímenes autoritarios (e marco escenográfico arquitectónico del nazismo, fascismo y franquismo)", Emblemata, no 12,2006 , pp. 275-288.

3 PIZZA, A.: "Malos tiempos para la lírica. Esperanza y des-esperanza en la Europa de posguerras" en POZO, JM. (Coord.): Los años 50: la arquitectura española y su compromiso con la historia. Pamplona, Universidad de Navarra, 2000, pp. 56-57.

4 DÍAZ SÁNCHEZ, J.: El triunfo del informalismo: la consideración de la pintura abstracta en la época de Franco. Madrid, Metáforas del Movimiento Moderno, 2000. 
El organismo que aglutinó un mayor número de revistas fue la Dirección General de la Arquitectura ${ }^{5}$ que editó tres publicaciones bajo la batuta de Carlos de Miguel: Revista Nacional de Arquitectura, Boletín de la Dirección General de Arquitectura y Gran Madrid ${ }^{6}$. El Boletín se convirtió en punto de encuentro para los descontentos con la situación de estancamiento que vivía la arquitectura ${ }^{7}$. Gabriel Alomar, Francisco Cabrero, José Marta Sostres, junto a Miguel Fisac fueron algunas de las firmas que manifestaron aquel desencanto. En el año 1947 aparecía en sus páginas una editorial titulada "Arquitectura Española" que llamaba la atención sobre el alto grado de "oficialismo" que había alcanzado la arquitectura europea y la necesidad imperante de una reflexión por parte de los arquitectos españoles:

"Los tiempos presentes, que todo lo han revuelto y desorbitado, llevan a la Arquitectura a una manifiesta desorientación. Y se da el caso de que, en tanto en los países democráticos impera un riguroso criterio funcionalista, en Rusia se impone la vuelta a la Arquitectura Clásica. Conviene que los arquitectos españoles pensemos muy seriamente en estos problemas para que, entre todos, animados de la mejor voluntad y afán de estudio, lleguemos a formar un criterio con personalidad propia.."

A partir de aquí se fueron sucediendo textos críticos donde buena parte de los arquitectos planteaban la necesidad de un cambio de estilo en el panorama español, dejando atrás la arquitectura monumental. Un grupo

5 La Dirección General de Arquitectura fue fundada por Ley el 23 de septiembre de 1939 con la intención de incorporar al Estado un organismo de control de la Arquitectura y los Arquitectos.

6 ASENJO ÁlVAREZ, F.: La nueva arquitectura. La contribución de las publicaciones periódicas de la Dirección General de Arquitectura (1948-1958). Tesis Doctoral, Madrid, Universidad de Alcalá de Henares, 2015, p. 257.

7 PÉREZ ESCOLANO, V.: Op. cit., p. 28.

8 RED.: "Arquitectura española", Boletín de Información de la Dirección General de Arquitectura, n. 5, 1947, p. 3. más reducido apuntaba incluso sobre la necesidad de mayor libertad expresiva que diera lugar a una nueva arquitectura acorde con los nuevos tiempos ${ }^{9}$. Uno de los primeros textos de marcado carácter renovador, publicado en el mes de junio de 1948 y considerado por varios autores como el punto de partida en la búsqueda de una nueva arquitectura, es el texto de Miguel Fisac titulado "Lo clásico y lo español" que dictaba sentencia en contra de cierta arquitectura monumental que se daba en España:

“¿Dónde está lo clásico en estas obras? Vemos con tristeza que está -que quiere estar- en esas pilastras, y cornisas, y frontones rotos o sin romper, en esas bolas $y$ en esos pináculos; en fin, en todo aquello que se ha pegado allí, venga o no a cuento. Y es natural, nos falló el principio; pero no porque sea falso, sino porque el frontoncito, las pilastritas, el entablamento o la cornisa no es lo permanente, es lo circunstancial, que perduró a través de algunos vaivenes clasicistas de la historia (...) ¿Qué es la arquitectura española? No voy a intentar definirla, ni creo, por otra parte, que sea algo tan concreto que quepa en una definición. Si tiene algo de común denominador puede ser esa reiteración de enfoque de problemas análogos a lo largo de nuestra Historia. Algo, en fin, que no se puede definir con un edificio" ${ }^{\prime 10}$.

El artículo del arquitecto manchego fue un claro ejemplo de la sensación que tenían la mayoría de los jóvenes que se veían en un callejón sin salida. El texto coincide en el tiempo con la construcción del Instituto Nacional de Óptica Daza de Valdés para el Consejo Superior de Investigación Científicas (1948), donde el arquitecto se empezó a liberar del lenguaje clasicista de

9 ESTEBAN, A.: “¿Modernidad o tradición? El papel de la RNA y el BDGA en el debate sobre las tendencias estilísticas de la arquitectura española" en POZO, J. M. (Coord.) Los años 50: la arquitectura española y su compromiso con la historia. Pamplona, Universidad de Navarra, 2000, p. 242.

10 FISAC, M.: "Lo clásico y lo español", Revista Nacional de Arquitectura, n. 78, 1948, pp. 197-198. 
obras anteriores y se intuyen algunas soluciones que llevó a la práctica posteriormente ${ }^{11}$. Pocos meses después se presentó un nuevo artículo por parte de Fisac titulado: "Las tendencias estéticas actuales"12. En sus palabras encontramos otro de los rasgos que caracterizan la búsqueda del estilo idóneo, el respeto y la asimilación de lo autóctono: "La nueva arquitectura que debemos crear no es algo quimérico sin correspondencia tangible con la realidad", sentencia el arquitecto.

\begin{tabular}{|c|c|l|}
\hline \multicolumn{3}{|c|}{$\begin{array}{l}\text { Tabla 1. Artículos de Miguel Fisac } \\
\text { en el Boletín de la Dirección General de Arquitectura }\end{array}$} \\
\hline N.o & Año & \multicolumn{1}{|c|}{ Artículos } \\
\hline 9 & 1948 & Las tendencias estética actuales \\
\hline 11 & 1949 & Estética de arquitectura \\
\hline 13 & 1949 & $\begin{array}{l}\text { La Liturgia en la Arquitectura religiosa. F. Iñiguez, L. Moya y M. } \\
\text { Fisac }\end{array}$ \\
\hline 14 & 1950 & Notas sobre Arquitectura Sueca \\
\hline 19 & 1951 & $\begin{array}{l}\text { El Arquitecto Alvar Aalto en Madrid. F. Chueca, R. Aburto, M. } \\
\text { Fisac, F. A. Cabrero }\end{array}$ \\
\hline 31 & 1954 & $\begin{array}{l}\text { Comentarios al fallo del Concurso de Anteproyectos para } \\
\text { Institutos laborales }\end{array}$ \\
\hline 40 & 1956 & Arte sacro en Salzburgo \\
\hline Fue:
\end{tabular}

Fuente: Elaboración propia a partir de los sumarios del Boletín de la Dirección General de Arquitectura
11 ASENJO ÁlVAREZ, F.: Op. cit., p. 225.

12 FISAC, M.: "Las tendencias estéticas actuales", Boletín Dirección General de Arquitectura, n.⒐ 1948, p. 21.
Los artículos se fueron sucediendo y el debate tomó tal importancia que uno de los tres bloques de la V Asamblea Nacional de Arquitectos ${ }^{13}$ llevaba por título "Tendencias estéticas de la arquitectura moderna", convirtiéndose en el tema que más interés despertó de los propuestos a debate ${ }^{14}$. En las ponencias y coloquios se pudo ver cuál era la situación del ejercicio de la profesión arquitectónica en España. Tal fue el interés hacía la asamblea que la Revista Nacional de Arquitectura y el Boletín de la Dirección General de Arquitectura recogieron en sus páginas varias de las ponencias presentadas ${ }^{15}$. En ellas se exponían múltiples enfoques que abarcaron desde la postura de escepticismo de José Fonseca ${ }^{16}$, hasta la propuesta de Juan de Zavala que abogó por la búsqueda de un nuevo camino debido al agotamiento del modelo oficial: "esto se revela simplemente con ojear las revistas extranjeras que nos llegan: parece que no sólo el texto, sino la imágenes hablan en otro idioma" ${ }^{17}$. Se publicó la ponencia que Miguel Fisac presentó en la que el arquitecto achacó la falta de verdad en la producción española y animó a sus compañeros a dejar de lado los pastiches y buscar en los orígenes de la verdadera historia:

“En los cambios de impresiones con otros compañeros sobre la calidad estética que debería tener nuestra arquitectura; en los artículos sobre estos temas que han ido apareciendo últimamente en nuestras revistas, $y$

13 La V Asamblea Nacional de Arquitectura se celebró en mayo de 1949 en las ciudades de Barcelona, Valencia y Palma de Mallorca. La reunión fue convocada por la Dirección General de Arquitectura y el Consejo Superior del Colegio de Arquitectos.

14 SAMBRICIO, C.: "De la arquitectura del nuevo estado al origen de nuestra contemporaneidad: el debate sobre la vivienda en la década de los cincuenta", Ra. Revista de arquitectura, n.ㅇ 4, 2000, pp. 75-76.

15 ESTEBAN, A.: Op. cit., pp. 242-243.

16 FONSECA, J.: "Tendencias actuales de la Arquitectura", Boletín de la Dirección General de Arquitectura, n.ㅇ 11, 1949, pp. 3-5.

17 ZAVALA, J.: "Tendencias actuales de la Arquitectura", Revista Nacional de Arquitectura n. 90,1949, p. 36 
en las ponencias que sobre las Tendencias actuales de la arquitectura presentan a la $V$ Asamblea de Arquitectos nuestro compañero Zavala y el Colegio Vasco-Navarro, se observa una evidente unanimidad, por lo menos en lo fundamental. Todos estamos de acuerdo en la necesidad de abandonar el camino que seguíamos, por faltarle contenido vital. Estamos de acuerdo también en la necesidad de renovación"18

El resultado de esta tertulia profesional se convirtió en un punto de inflexión marcando el retorno de la arquitectura moderna a nuestro país. Diez años antes se había celebrado la I Asamblea de Arquitectos organizada por la Dirección General de Arquitectura dependiente entonces del Ministerio de la Gobernación. A ella acudieron los principales arquitectos simpatizantes con el gobierno franquista mostrando su disposición para servir al Nuevo Estado ${ }^{19}$. En la asamblea de 1949 se dejó atrás la arquitectura de connotaciones ideológicas que fue impuesta finalizada la contienda.

La sensación de agotamiento que estaba en el trasfondo de la arquitectura española se empezó a plasmar en las revistas especializadas. Los artículos, obras, concursos, congresos y exposiciones que aparecían en sus páginas permiten identificar cuales fueron los acontecimientos más relevantes, el origen de nuevas ideas y definir los límites de esa intensa investigación. En los años cincuenta estas revistas cumplían con varias funciones: facilitaban la configuración de un discurso de modernidad arquitectónica en nuestro país, daban a conocer aquellos episodios más relevantes que se producían en el panorama internacional propio y servían de elemento de difusión de la producción nacional en el extranjero ${ }^{20}$. Dentro de las revistas de

18 FISAC, M.: "Estética de la Arquitectura", Boletín de Dirección General de Arquitectura, n.o 11, 1949, p. 13.

19 VV. AA.: Asamblea Nacional de arquitectos los días 26, 27, 28 Y 29 de junio de 1939. Madrid, Servicios Técnicos de FET y de las JONS, Sección de Arquitectura, 1939.

20 DURÁ GÚRPIDE, I.: "La revista como referencia, testigo y difusora de la nueva arquitectura de la época tuvo una especial relevancia la Revista Nacional de Arquitectura, publicación que desde 1941 dependía de la Dirección General de Arquitectura con Pedro Muguruza como su primer director. La tendencia de la revista cambió completamente con respecto a los años anteriores al conflicto, y publicó en sus páginas una arquitectura historicista en la que no se hizo concesiones a la modernidad ni a las vanguardias extranjeras ${ }^{21}$. Es muy significativo que a partir del año 1948 la revista volvió a pertenecer al Colegio de Arquitectos de Madrid y se inició una nueva etapa bajo la larga dirección de Carlos de Miguel. El formato y el aspecto se modificaron, y rápidamente aparecieron textos y proyectos de los arquitectos jóvenes del momento: Cabrero y Aburto, Coderch y Valls, Sota, Fisac, Saenz de Oiza, Corrales y Molezún, etc ${ }^{22}$. Una significativa parte del contenido de la revista eran artículos con un carácter marcadamente divulgador, no se trata de textos originales escritos para la ocasión, solían ser fragmentos de memorias acompañadas de amplios reportajes fotográficos y documentación gráfica.

La fotografía tuvo un papel crucial en la definición y consolidación de la imagen de la arquitectura moderna española, en un momento en que los contactos y viajes resultaban relativamente escasos todavía, como apunta Ana Esteban Maluenda: "buena parte de la producción del momento se leyó bajo el canon interpretativo de una serie de fotógrafos que, a través de sus instantáneas, fueron transmitiendo la realidad que soñaban. La fotogenia de algunos proyectos fue un elemento decisivo en la búsqueda

arquitectura escolar" en POZO, JM.; GARCÍA-DIEGO, H. y CABALLERO, B. (coord.): Las revistas de arquitectura (1900-1975): crónicas, manifiestos, propagandas. Pamplona, T6) Ediciones, 2012, p. 464.

21 CAPITEL, A.: "Notas sobre los avatares históricos de la revista Arquitectura como medio de difusión de la innovación arquitectónica", Informes de la construcción, no 60, 2008, pp. $45-48$.

22 ASENJO ÁlVAREZ, F.: Op. cit., p. 260. 
de la normalización del lenguaje de la modernidad, deudora, sin lugar a dudas, de la estética que transmitió la fotografía del momento." 23

Las obras del arquitecto manchego aparecían con frecuencia en las páginas de la revista, mostrándose como uno de los arquitectos protagonistas del encuentro con la modernidad. Por su participación en todo el proceso de debate y la divulgación de su obra, el prestigio de Miguel Fisac subió como la espuma, convirtiéndose en el paradigma de los nuevos tiempos.

Las Sesiones de Críticas de Arquitectura (1950-1964), organizadas por la Revista Nacional de Arquitectura, fue otro campo de debate en torno al panorama arquitectónico español. En estas reuniones organizadas y publicadas en la revista se presentaron a debate numerosos temas de la actualidad. A través de ellas se pudo detectar cuáles eran los intereses que movían a los arquitectos del momento. El ciclo se inauguró en 1950 dedicado al edificio de la ONU en Nueva York. Esta primera asamblea se planteó con la misma estructura que tuvieron las siguientes: un ponente invitado por la organización realizaba una exposición del tema elegido pasando el turno, a continuación, al resto de asistentes para que expresaran su opinión. De esta forma, cada sesión generó una mesa redonda en la que se debatieron los argumentos presentados ${ }^{24}$. La mayoría de las Sesiones de Crítica se dedicaron a cuestiones directamente relacionadas con el ámbito español, únicamente se convocaron algunas reuniones dedicadas a temas extranjeros y, en muchos casos, con algún tipo de motivo que las relacionaba con España. Las sesiones que alcanzaron mayor éxito fueron las dedicadas a edificios concretos, en ellas se discutía sobre aspectos de concepto o constructivos que interesaban a

23 ESTEBAN MALUENDA, A.: “Una España Moderna. La fotografía como herramienta para la creación de una imagen de la arquitectura" en Encontro da Associação Nacional de Pesquisa e Pós-Graduação, Porto Alegre, Arquitetura e Urbanismo, 2016, p. 3.

24 ESTEBAN, A.M.: “¿Modernidad o tradición?...”, Op. cit., p. 245.
Tabla 2. Artículos sobre la obra de Miguel Fisac en la Revista Nacional de Arquitectura ${ }^{25}$.

\begin{tabular}{|c|c|l|}
\hline N.o & Año & \\
\hline 75 & 1948 & $\begin{array}{l}\text { Anteproyecto de Palacio Provincial y Gobierno Civil en Murcia. } \\
\text { Miguel Fisac y Daniel Carbonell }\end{array}$ \\
\hline 102 & 1950 & Instituto de Óptica Daza de Valdés. Madrid \\
\hline 108 & 1950 & $\begin{array}{l}\text { Local para el Consejo Superior de Investigaciones Científicas. } \\
\text { Madrid }\end{array}$ \\
\hline 109 & 1951 & Viviendas en cadena \\
\hline 118 & 1951 & Casa de vivienda. Madrid \\
\hline 127 & 1952 & Un nuevo ladrillo \\
\hline 139 & 1953 & Instituto Laboral en Daimiel. Ciudad Real \\
\hline 143 & 1953 & Una tienda en "Los Sótanos". Madrid \\
\hline 145 & 1945 & Pabellón de Ciudad Real en la Feria del Campo. Madrid \\
\hline 148 & 1954 & Más sobre casas en cadena \\
\hline 157 & 1955 & Colegio Apostólico de los PP. Dominicos. Valladolid \\
\hline 175 & 1956 & Silla \\
\hline 175 & 1956 & Centro de Investigaciones Biológicas. Madrid \\
\hline 176 & 1956 & Poblado del Zofio \\
\hline 186 & 1957 & Vivienda unifamiliar. Madrid \\
\hline 196 & 1958 & Las nuevas parroquias de Vitoria. Miguel Fisac, Javier Carvajal \\
\hline 203 & 1958 & $\begin{array}{l}\text { Conjunto de edificios para formación del profesorado de } \\
\text { enseñanza laboral en la ciudad universitaria, Madrid }\end{array}$ \\
\hline & Fuente: elaboración propia a partir los sumarios de la Revista Nacional de Arquitectura \\
\hline & & \\
\hline 145 & & \\
\hline 145 &
\end{tabular}

25 Quedan fuera de esta tabla la participación del arquitecto en artículos de opinión y debate. Algunos de ellos son: "Lo clásico y lo español" (n.o 78, 1948), "Artes plásticas" (no 78, 1948), "Homenaje a Daniel Vázquez Díaz" (n.o 148, 1953), "Impresiones sobre la obra de Gaudí" (n.o 179, 1956), entre otros. 
los asistentes $y$, en muchas ocasiones, el arquitecto autor del proyecto estaba presente o era el encargado de realizar la ponencia de presentación. La responsabilidad de su organización periódica recayó sobre arquitectos como Fernando Chueca, Luis Moya o Carlos de Miguel, entre otros ${ }^{26}$. Fisac tuvo un papel relevante en las mismas, ya que participó en un importante número de las reuniones y se dedicó algunas de ellas a la presentación de sus obras: la Iglesia de los Padres Dominicos de Valladolid ${ }^{27}$, la Parroquia de la Coronación en Vitoria ${ }^{28}$ y los edificios para el Centro de Formación del Profesorado Laboral en la Ciudad Universitaria de Madrid ${ }^{29}$.

Vinculado a las Sesiones de Crítica de Arquitectura aparece el conocido como "Manifiesto de la Alhambra". Fue una reunión extraordinaria de las Sesiones de la Revista Nacional de Arquitectura, en la que un grupo de arquitectos se retiró durante varios días para "meditar sobre las bases de una nueva arquitectura española" ${ }^{30}$. La tertulia, realizada en la ciudad de Granada, generó un manifiesto cuya redacción definitiva fue encargada a Fernando Chueca Goitia quien resumió las ideas debatidas dándoles forma literaria. Basándose en las características de la arquitectura hispanoárabe los arquitectos dejaron patente la necesidad de búsqueda de unos nuevos espacios constructivos evitando la monumentalidad vigente en la arquitectura española. El encuentro se celebró durante los días 14 y 15 de octubre de 1952 en los palacios nazaríes. La difusión del acto fue amplia y, como origen de éste, la sesión de crítica granadina apareció en la mayoría

26 SOLANA, E.: “Granada, 1953. El manifiesta de la Alhambra”, Revista de Edificación RE, n.o 17, 1994, p. 71.

27 "Sesión de Crítica de Arquitectura dedicada a la iglesia de los PP. Dominicos en Valladolid", Revista Nacional de Arquitectura, n.o 157, 1955, pp. 10-19.

28 "Sesión de Crítica de Arquitectura. Las nuevas parroquias de Vitoria", Revista Nacional de Arquitectura, n.o 196, 1958, pp. 1-15.

29 "Visita y opiniones al edificio para la formación del profesorado de enseñanza laboral", Revista Nacional de Arquitectura, n. 203, 1958, pp. 3-10.

30 SOLANA, E.: Op. cit., p. 72. de revistas de la época. Estos arquitectos buscaron en La Alhambra el paradigma de la arquitectura española, abandonando los supuestos herrerianos e intentando encontrar las relaciones de ésta con la nueva arquitectura contemporánea, teniendo como uno de sus principales objetivos el no quedarse aislados del movimiento moderno que se desarrollaba en otros países. Los objetivos iniciales del manifiesto supusieron un avance mayor que las conclusiones redactadas con posterioridad, puesto que representaban una auténtica toma de postura, mientras que las conclusiones, en la mayoría de los casos, no superaron las ambiciosas intenciones de las propuestas. El Manifiesto de lo Alhambra apareció publicado en enero de 1953 firmado por los arquitectos participantes en la sesión entre los que se encontraba Miguel Fisac. En la Revista Nacional de Arquitectura se adelantaron algunas de las opiniones y conclusiones del singular encuentro, entre ellas algunas del arquitecto manchego:

"Yo veo en la Alhambra, como elemento arquitectónico esencial, el aire, el aire quieto. Después el agua; agua en movimiento, como expresión de vida. Las superficies que limitan este aire quieto son las que dan lugar a las formas espaciales. La vegetación se incorpora a todo este conjunto. E dar el principal papel en arquitectura al aire, al agua, a la naturaleza, exige del arquitecto una posición de humildad amorosa. Los arquitectos de la Alhambra nos dan un gran ejemplo. Han obrado humildemente" ${ }^{31}$

El manifiesto tuvo una repercusión limitada en la arquitectura española debido a múltiples e interactivos factores, entre los cuales cabría destacar la heterogeneidad de sus firmantes, el no seguimiento de sus principios por parte de algunos de ellos, lo difuso de sus conclusiones y lo tardío de su redacción ${ }^{32}$.

31 VV. AA.: "Sesión de crítica de arquitectura celebrada en la Alhambra los días 14 y 15 de octubre de 1952", Revista Nacional de Arquitectura, n.o 136, 1953, p. 20.

32 GRIJALBA, A.: "Del campo a la ciudad. Los frenéticos cincuenta" en POZO, J. M. y 
Coincidiendo con este periodo de apertura y entusiasmo profesional, que no se vivía desde antes a la Guerra Civil, muchos arquitectos empezaron a realizar viajes al extranjero para entrar en contacto con la realidad internacional, ya que se había producido un paréntesis de casi quince años de aislamiento solamente roto por escasas revistas de arquitectura que llegaban a nuestro país. Buena parte de los viajes fueron financiados por organismos oficiales y se centraron en su mayoría en países europeos. Cabrero viajó a centroeuropea en 1950, Vázquez Molezún estuvo en Roma de 1949 a 1952 y García Paredes visitó distintos países europeos de 1950 a $1952^{33}$. Miguel Fisac efectuó un recorrido por varias ciudades europeas en el año 1949. Durante este periodo estaba trabajando para el Consejo Superior de Investigaciones Científicas realizando el proyecto para la construcción del Centro de Investigaciones Biológicas de los Patronatos Cajal y Ferrant, y como parte del estudio previo del programa para los laboratorios, el viaje tuvo como objetivo principal conseguir información directa sobre la estabulación de animales de experimentación: ratas, ratones, cobayas, etc., proporcionando al arquitecto la ocasión de visitar centros de investigación en Lausanne, Basel, París, Copenhague, Estocolmo, Goteborg y Ámstedam. Fisac se encontró con interesantes propuestas arquitectónicas descubriendo la arquitectura nórdica y en concreto las obras de Arne Jacobsen y Erik Gunnar Asplund ${ }^{34}$.

TRUEBA, I. (coord.): Arquitectura, ciudad e ideología antiurbana. Pamplona, T6 Ediciones, 2002, pp. 110-111.

33 URRUTIA, A.: Historia de la arquitectura española. Madrid, Cátedra, 1997, p. 516.

34 TOMÁS GABARRÓN, L. y GRANAdOS GONZÁLEZ, J.: “Historia de una búsqueda: La influencia de los viajes en la obra de Miguel Fisac" en Actas del I Congreso Pioneros de la Arquitectura Moderna Española: Vigencia de su pensamiento y Obra. Madrid, Fundación Alejandro de la Sota, 2014, pp. 940- 950.

\section{EL INSTITUTO LABORAL DE DAIMIEL: REFERENTE EN LA ARQUITECTURA MODERNA}

Fisac no sólo jugó un importante papel dentro del debate ideológico sino que su obra se convirtió en un referente de su tiempo. A la vuelta del viaje europeo ejecutó un importante giro en su estilo constructivo que lo convirtió en "la figura estelar" de la época ${ }^{35}$. Debido al éxito obtenido por los edificios construidos para el Consejo Superior de Investigaciones Científicas, el Ministro Ibáñez Martín le encargó la edificación del Instituto Laboral de Daimiel como respuesta a una petición directa que Fisac le hizo, donde pedía la construcción en su pueblo natal de uno de los nuevos institutos. En el decreto de 10 de Agosto de 1950 se autorizó por parte del ministerio la creación en Daimiel de un Centro de Enseñanza Media y Profesional de modalidad Agrícola y Ganadera. El proyecto de los institutos laborales fue un fiel reflejo de la política económica y educativa del gobierno de Francisco Franco durante su primer periodo. El Nuevo Régimen surgido tras la guerra optó por la agricultura como motor de la reconstrucción del país. Fue más una necesidad, había que levantar la economía a partir de lo que se disponía; un estado agrario y preindustrial con la mitad de la población activa campesina. El gobierno se hizo eco de esta situación y proporcionó a un importante sector de la población, situada lejos de los núcleos urbanos importantes, el acceso a la formación de carácter secundario y técnico ${ }^{36}$. El nuevo Bachillerato se impartió en Centros de Enseñanza Media y Profesional, denominados popularmente como Institutos Laborales, que se establecieron en cabeceras de comarcas alejadas de los núcleos importantes de población que tenían acceso a otro tipo de instituciones educativas ${ }^{37}$. El Plan Nacional de creación de Institutos

35 URRUTIA, A.: Op. cit., p. 1882.

36 ESTEBAN, A. M.: “¿Modernidad o tradición?, Op. cit., pp. 97-106.

37 CAPITEL, A.: "La arquitectura de los edificios de la enseñanza laboral en la España de la Dictadura" en Actas VIII DOCOMOMO Ibérico. La arquitectura del Movimiento 
Laborales estableció rigurosamente la ubicación de los centros, creando tres modalidades diferentes: agrícola-ganadera, industrial-minera y marítimo- pesquera. (Fig. 1)

Cuando se planteó la construcción de los primeros edificios educativos en la España franquista apenas existían referentes nacionales en cuanto a arquitectura docente. La educación en España había dependido históricamente de iniciativas privadas, órdenes religiosas mayoritariamente, y su lenguaje arquitectónico grandilocuente estaba pensado más desde la representatividad de la institución que desde necesidades educativas reales. En la década de los veinte se produjo un primer movimiento hacia la depuración del lenguaje arquitectónico educativo a través de la Oficina Técnica de Construcciones Escolares, una compleja organización a la que se le otorgaron competencias sobre la ejecución de proyectos de escuelas. La Oficina estaba dotada de un arquitecto jefe, cinco arquitectos proyectistas y otros profesionales necesarios para el desarrollo de sus funciones; a las órdenes del Director de la Oficina que designó a una serie de arquitectos directores de obra, uno por provincia, excepto en el caso de Madrid, cuyo cargo era asumido directamente por él ${ }^{38}$. Al frente de la Oficina estuvo desde su fundación Antonio Flórez, que tuvo un papel trascendental en la definición de sus modelos arquitectónicos debido a su amplia experiencia en la construcción de edificios educativos ${ }^{39}$. La creación de la Oficina Técnica supuso un salto cualitativo para el desarrollo de la arquitectura docente. A partir de este momento los proyectos para las escuelas fueron realizados por arquitectos

Moderno y la educación. Madrid, Ministerio de Educación Cultura y Deporte, 2015, pp. 107-112.

38 LAHOZ ABAD, P.: "Los modelos escolares de la oficina técnica para la construcción de escuelas", Historia de la Educación, n.o 12-13, 1993-1994, p. 122.

39 GUERRERO, S.: Antonio Flórez, arquitecto, (1877-1941). Madrid, Residencia de Estudiantes, 2002. especializados planteando edificios con claros criterios de funcionalidad. Durante el periodo de la Segunda República se vivió un ciclo de gran actividad al ponerse en marcha los planes de construcciones escolares con los que el Estado quiso resolver el problema de la escuela nacional. Tras el paréntesis provocado por la guerra se llegó a la década de los cincuenta sin logros significativos en el ámbito educativo. Durante este periodo la necesidad de crear nuevos centros escolares y la escasez de medios fueron las condiciones aptas para la experimentación de nuevas posibilidades. Con este propósito, desde el Ministerio de Educación se convocó varios concursos como el de modelos de escuelas (uno de tipo unitario en 1956 y otro de graduado en 1958) y el de Institutos Laborales de 1954. Estas propuestas coincidieron con la puesta en marcha de un Plan Nacional de Construcciones Escolares a partir de 1956 y la implantación del proyecto de institutos laborales. Este contexto propició a los arquitectos un importante campo de cultivo para el desarrollo de propuestas novedosas. Al mismo tiempo fue uno de los temas recurrentes en las revistas donde alcanzó un importante número de referencias entre artículos teóricos y obras tanto españolas como extranjeras ${ }^{40}$.

Fisac se convirtió en un pionero y referente en esta nueva etapa de la arquitectura docente. En 1950 diseñó el Instituto laboral de Daimiel (Ciudad Real), un año más tardé inició la construcción de otro Instituto en Almendralejo (Badajoz) y en 1952 otro en Hellín (Albacete). En estas construcciones puso sobre la mesa todos los elementos que presidió la gestación de una nueva tipología arquitectónica que fue ampliamente utilizada en años venideros, y despertó un gran interés entre los compañeros de profesión ${ }^{41}$, por ejemplo en octubre de 1952, después de la

40 DURÁ GÚRPIDE, I.: Op. cit., p. 455

41 BERGERA, I.: "Institutos laborales: de la teoría a la práctica" en POZO, JM. (coord.): Los años 50: La arquitectura española y su compromiso con la historia. Pamplona, T6 Ediciones, 2002, pp. 195-207. 
celebración en Granada de las Sesiones del Manifiesto de la Alhambra, Carlos de Miguel, Cabrero, Aburto y Fisac realizan juntos el viaje hacia a Madrid y visitaron el centro que se encontraba todavía en obras. En 1954 desde el Ministerio de Educación se planteó la necesidad de convocar un concurso nacional entre arquitectos para proyectar las futuras construcciones de institutos laborales ${ }^{42}$. El concurso resultó, sin duda revelador, por los precedentes, por los arquitectos que intervinieron y por la respuesta de éstos que llevó consigo la obtención de buenos resultados. Carlos de Miguel solicitó a Fisac publicar en la revista un artículo sobre el Instituto de Daimiel, para orientar a los que se presentaron ${ }^{43}$.
En el año 1950 Miguel Fisac comenzó la construcción del centro educativo castellano-manchego, el primer edificio considerado por él mismo como moderno ${ }^{44}$. En él se visualizan algunos cambios importantes como la preocupación por el espacio, la utilización de técnicas de tradicionales, el protagonismo de los detalles, el diseño de la totalidad del edificio y las ordenaciones de los elementos que los configuran. Juan Daniel Fullaondo describe estos años como de "experimentación" ${ }^{45}$ y podemos rastrear las diferentes influencias en la obra del arquitecto que se pueden resumir en varios ejes: las arquitecturas hispano-árabe, japonesa y nórdica. (Fig. 2)

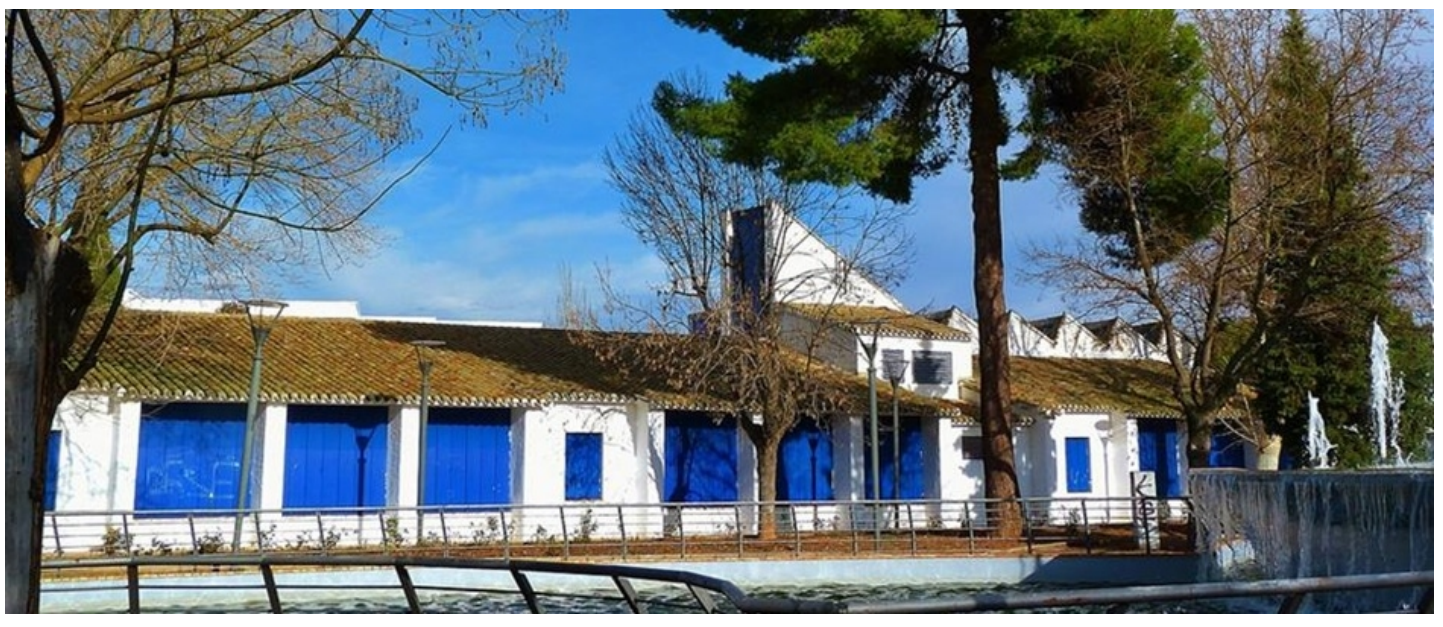

Fig. 1: Vista exterior del Instituto Laboral de Daimiel, en la actualidad el I.E.S. Ojos del Guadiana

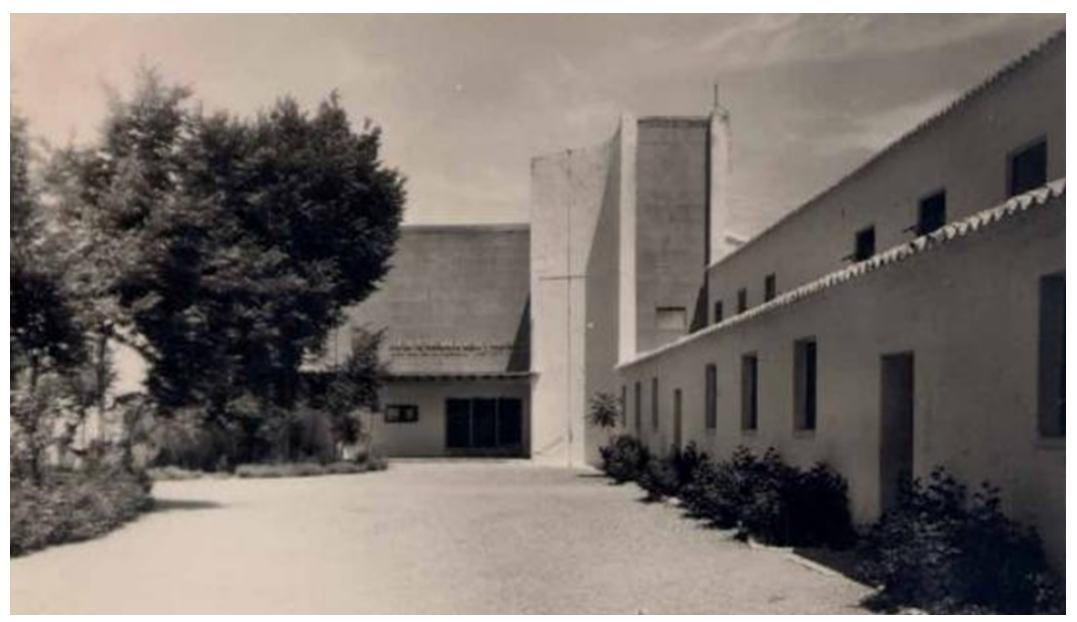

Fig. 2: El Instituto Laboral de Daimiel en los años cincuenta. Archivo de la Fundación Fisac
42 VALCÁRCEL, C. M.: "Concurso de Institutos Laborales: Presentación", Revista Nacional de Arquitectura, n.o 153, 1954, p. 1.

43 FISAC, M.: "Instituto Laboral en Daimiel", Revista Nacional de Arquitectura, n.o 139, 1953, pp. 3-14.
44 CALERO, A.: "Miguel Fisac: La arquitectura es un trozo de aire humanizado", Añil, n.ㅇ 14, 1998, p. 46.

45 FULLAONDO, J. D.: Miguel Fisac. Madrid, Dirección General de Bellas Artes, 1972, p. 8. 
La configuración del Instituto Laboral se realizó a través de una serie de elementos típicos de la arquitectura popular manchega como tejas, tapial, encalados, tinajas... pero con un planteamiento totalmente distinto, consiguiendo despegarse de una interpretación trivial de lo popular y alcanzar el tono poético que caracterizó a sus obras. Durante los años cincuenta recurrió en varias ocasiones a lo popular como material principal de sus edificios con la finalidad de evitar elevados costes económicos, pero dotando a estos elementos de una estética acorde a sus tiempos. Fisac no fue el único que inició esta vía de utilización de lo vernáculo y la tradición como camino a la modernidad, por ejemplo Fernández del Amo propugnó en sus poblados de colonización una arquitectura con matices europeos conviviendo con muros de tapial. En Miguel Fisac la valoración de lo popular también se puede rastrear en sus planteamientos teóricos dispersos en varias obras publicadas en aquellos años donde analizó las posibilidades que proporcionaba la arquitectura popular:

"La casita que se construye en un lugar sigue siempre no sólo ligada al paisaje por vínculos de clima, de color y de ambiente físico, sino también a otros morales, etnológicos, de idiosincrasia de los habitantes de la región... Esa idiosincrasia ha creado espontáneamente una Arquitectura popular -riquísima en España-; copiarla alegremente acarrea los tristes resultados que tan abundantemente conocemos, pero desconocerla $\mathrm{u}$ olvidarla es privarse de un gran medio" ${ }^{46}$

El edificio se construyó en unos terrenos a las fueras de la localidad manchega, después de superar cierta oposición que encontró por parte de las autoridades locales. Miguel Fisac se planteó como principal objetivo crear una serie de ambientes donde fuera posible realizar unas determinadas actividades. El programa propuesto para el Instituto de Daimiel estaba formado por cinco aulas con un despacho adjunto para el

46 FISAC, M.: “Las Tendencias Estéticas Actuales", Boletín de la Dirección General de Arquitectura, n.ㅇ 9, 1948, p. 9. profesor y archivo de material pedagógico; un aula de dibujo; un taller de ajuste; otro de máquinas y un laboratorios de química; un salón de actos que a la vez se utilizó como sala de proyección; una biblioteca y un núcleo de dirección. A partir de esas necesidades se hizo un estudio de cada uno de los elementos del programa, su superficie, volumen, forma y orientación. En el análisis de cada uno de los elementos el arquitecto hizo especial hincapié en cuanto al estudio de la morfología en plantas, alzados, propiedades de iluminación, climáticas, aislamiento acústico e insonorización ${ }^{47}$. (Fig. 3)

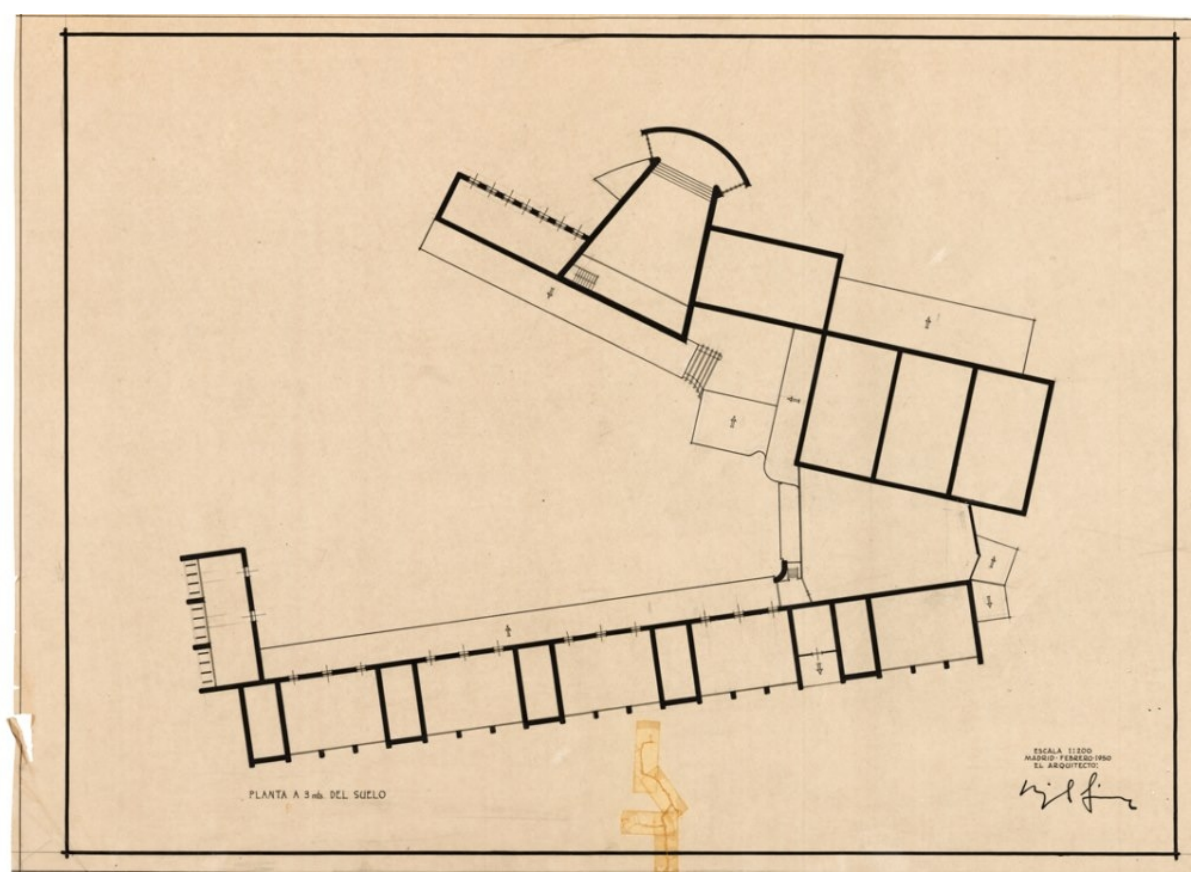

Fig. 3: Planta del edificio del Instituto Laboral de Daimiel. Archivo de la Fundación Fisac

47 FERNANDEZ GALIANO, L.: "Instituto Laboral de Daimiel", A\&V Monografías: Miguel Fisac, n.o 101, 2003, p. 30 
Posteriormente realizó la ordenación de los elementos distribuyendo el edificio en dos partes bien diferenciadas; por un lado un grupo de aulas unidas por una larga galería y por otro una zona compuesta por talleres. Ambas se unían en el Salón de actos donde también se encontraba la zona de dirección. Alejados parcialmente del resto de dependencia se ubicó un gimnasio y un cobertizo que se ensamblaban al resto de la edificación a través de una galería porticada de pies derechos de madera abierta al exterior, dejando un espacio libre preparado para poder instalar allí una pequeña capilla que nunca llego a construirse. El diseño de ese espacio planteaba muchas similitudes con la construida poco después en el Colegio Apostólico de Arcas Reales en Valladolid. En el proyecto de capilla los muros laterales opacos tendían a unirse según se aproximaban a la zona del altar que se conjugaba con una elevación progresiva del suelo y techo hacia el presbiterio. El efecto dinámico de la planta de la iglesia se reforzaba aún más con una pequeña puerta lateral dejando atrás la entrada tradicional a los pies de la iglesia.

Dentro de estos espacios individualizados destacó el salón de actos, en su configuración se tuvo en cuenta que sirviera a la vez como elemento de recepción y de enlace de las diferentes partes del edificio. Estas condicionantes provocaron algunos problemas funcionales, una cabina de proyección que estaba planteado ubicar allí debía de situarse en un lugar que no perturbase la entrada del edificio y se producía una deformación en los visionados cinematográficos. Para corregir este defecto en el paramento del salón donde se sitúa la pantalla de proyección se colocó de forma que fuese normal a la bisectriz que formaba el eje general de la sala con el eje de proyección, mejoraron todos los puntos de vista del salón. Las cubiertas del salón se sustentaron con una serie de cerchas metálicas que marcaban el aspecto exterior en el edificio, y que permitían graduar la iluminación ocultándose tras un forro cuya sección se asemeja al perfil de las vigas-huesos que años más tarde realizó en hormigón. (Fig. 4)

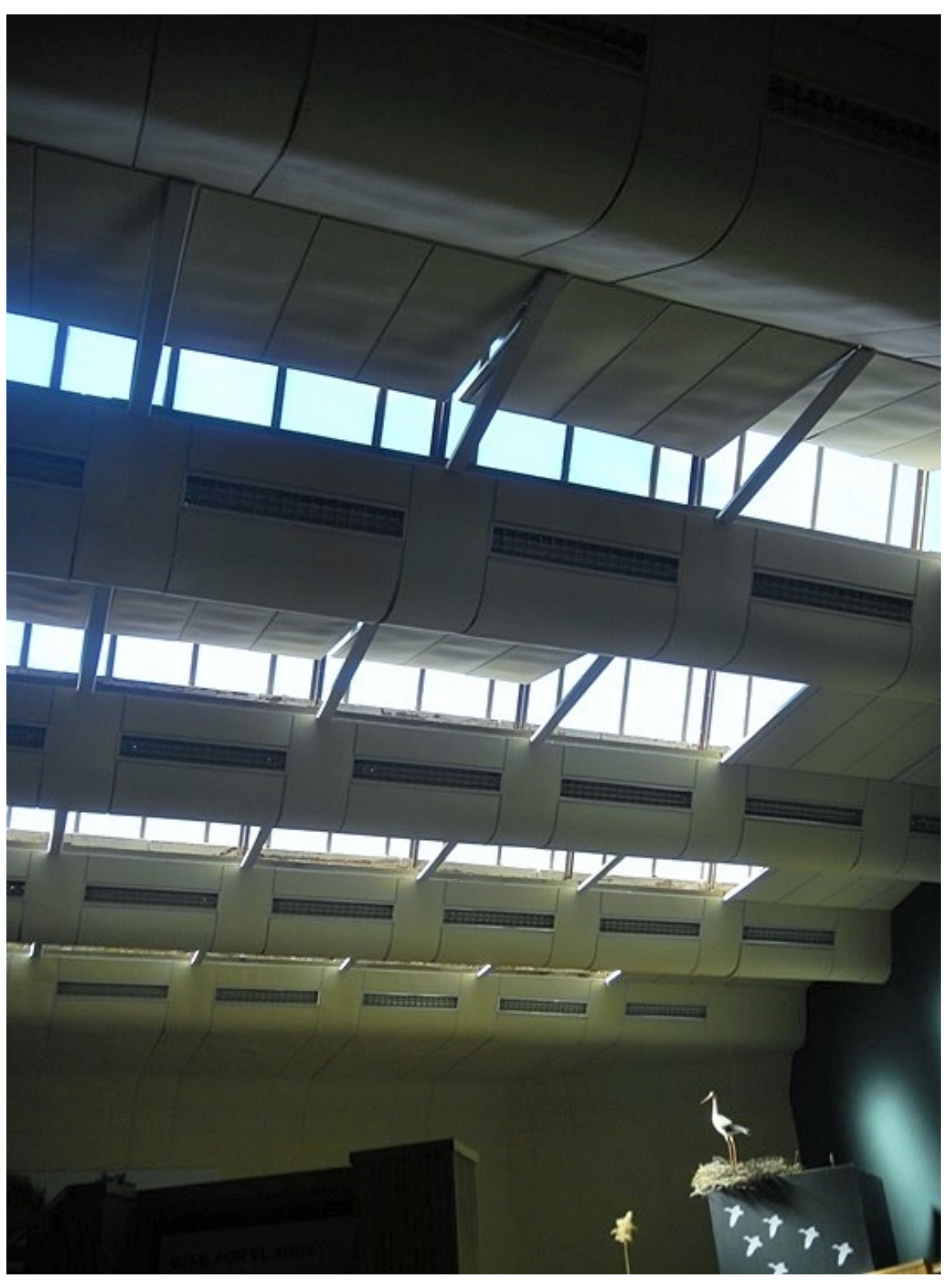

Fig. 4: Cubiertas del salón de actos del Instituto Laboral de Daimie 


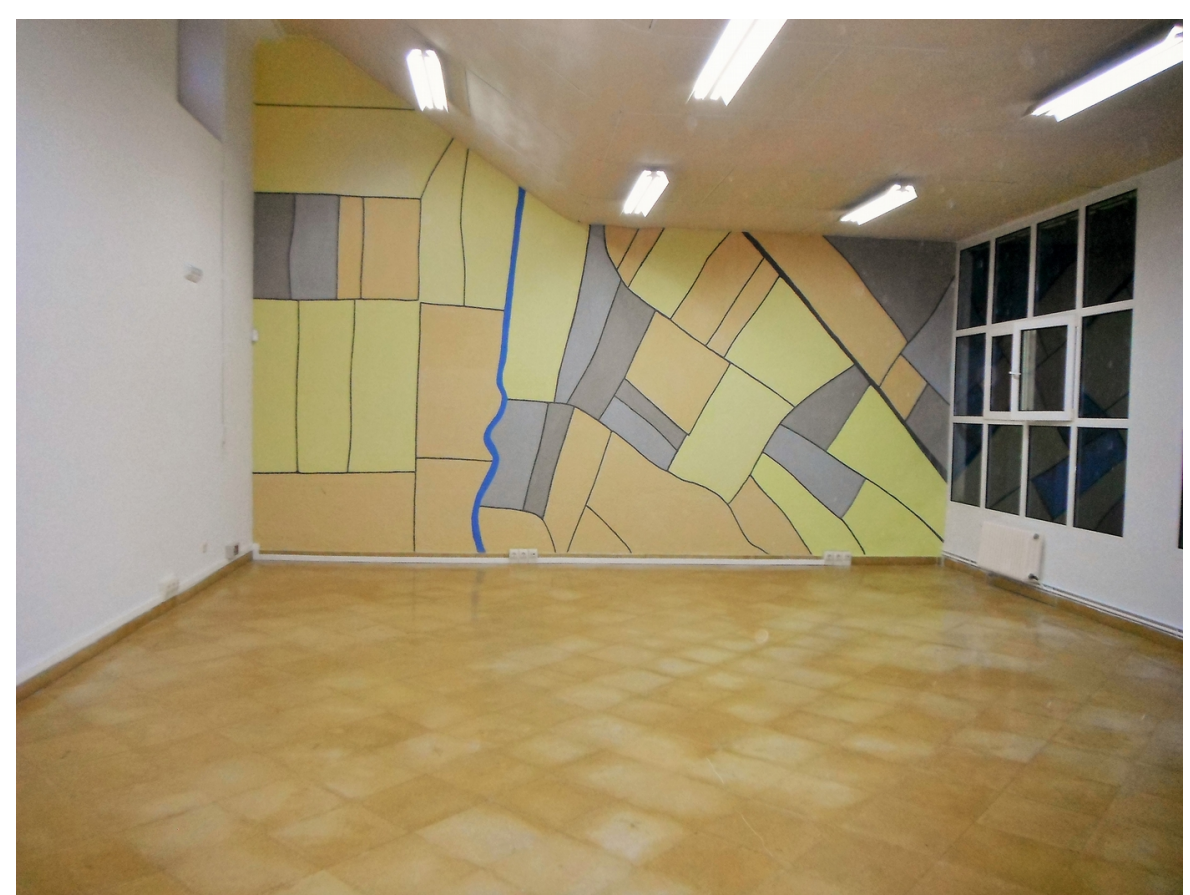

Fig. 5: Aula del Instituto Laboral de Daimiel

Las aulas del centro estaban perfectamente estudiadas en cuanto a cuestiones de iluminación, ya que contaban con unos amplios ventanales laterales abiertos al exterior para conseguir la mejor iluminación posible. Como protección frente al sol diseñó unos grandes paneles verticales de madera que giraban para conseguir regular y ocultar la luz. El techo destacaba por su silueta curva que sorprendente al espectador y que buscaba conseguir una perfecta dispersión acústica del espacio y al mismo tiempo servía como soporte de lámparas fluorescentes que diseño en 1949 y registró bajo el nombre de Blancanieves en $1956^{48}$. Los luminarios

48 Memoria descriptiva: "Pantalla soporte para tubo de luz", Memoria de Patente: conseguían matizar de forma sencilla todo el espacio interior mediante la rítmica disposición de la luz cenital. En los lados menores de las aulas el arquitecto realizó unas pinturas murales basada en composiciones geométricas que se inspiraban en paisajes de La Mancha vistos desde altura. Cada una de las pinturas murales fue ejecutada en una gama distinta de color con la finalidad de representar las cuatro estaciones y los alumnos no las visualizaban ya que se encontraban de espaldas a ellas con el fin de no distraer su atención. (Fig. 5)

Uno de los aspectos donde más quedó patente la influencia nórdica del conjunto fue en el ejercicio de diseño de todos los elementos que formaban el edificio. El arquitecto los diseñaba y contaba para su elaboración con artesanos locales ante la inexistencia en el mercado español de muebles acordes con una estética moderna, creando soluciones ingeniosas como la barandilla de la escalera de acceso al torreón que servía a su vez como conducto que canalizaba agua del aljibe. En el mobiliario utilizó una técnica novedosa para el tratamiento de la madera que él denominó como "desalburizada". Fisac utilizó madera de pino tratada con cal para resaltar la veta y posteriormente rascarla con un cepillo de púas metálicas para eliminar la cal. El mobiliario constaba de diversas piezas como mesas, estanterías, sillas... todas ellas con un sobrio diseño de influencia nórdica ${ }^{49}$. En el Instituto Laboral de Daimiel podemos ver como las novedades arquitectónicas que se empezaron a implantar en España tuvieron un reflejo directo en el diseño del mobiliario. En los pequeños matices del edificio se puede observar un intenso sabor nórdico en el sencillo diseño formado a base de las sencillas curvas como en los pi-

ES0118812, Oficina Española de Patentes y Marcas, 1956.

49 AGUILO ALONSO, M. P.: "Acerca del diseño: Miguel Fisac y el mobiliario del Consejo Superior de Investigaciones Científicas" en X Jornadas de Arte El arte español del siglo $X X$. Su perspectiva al final del milenio. Madrid, Consejo Superior de Investigaciones Científicas, 2001, p. 82 


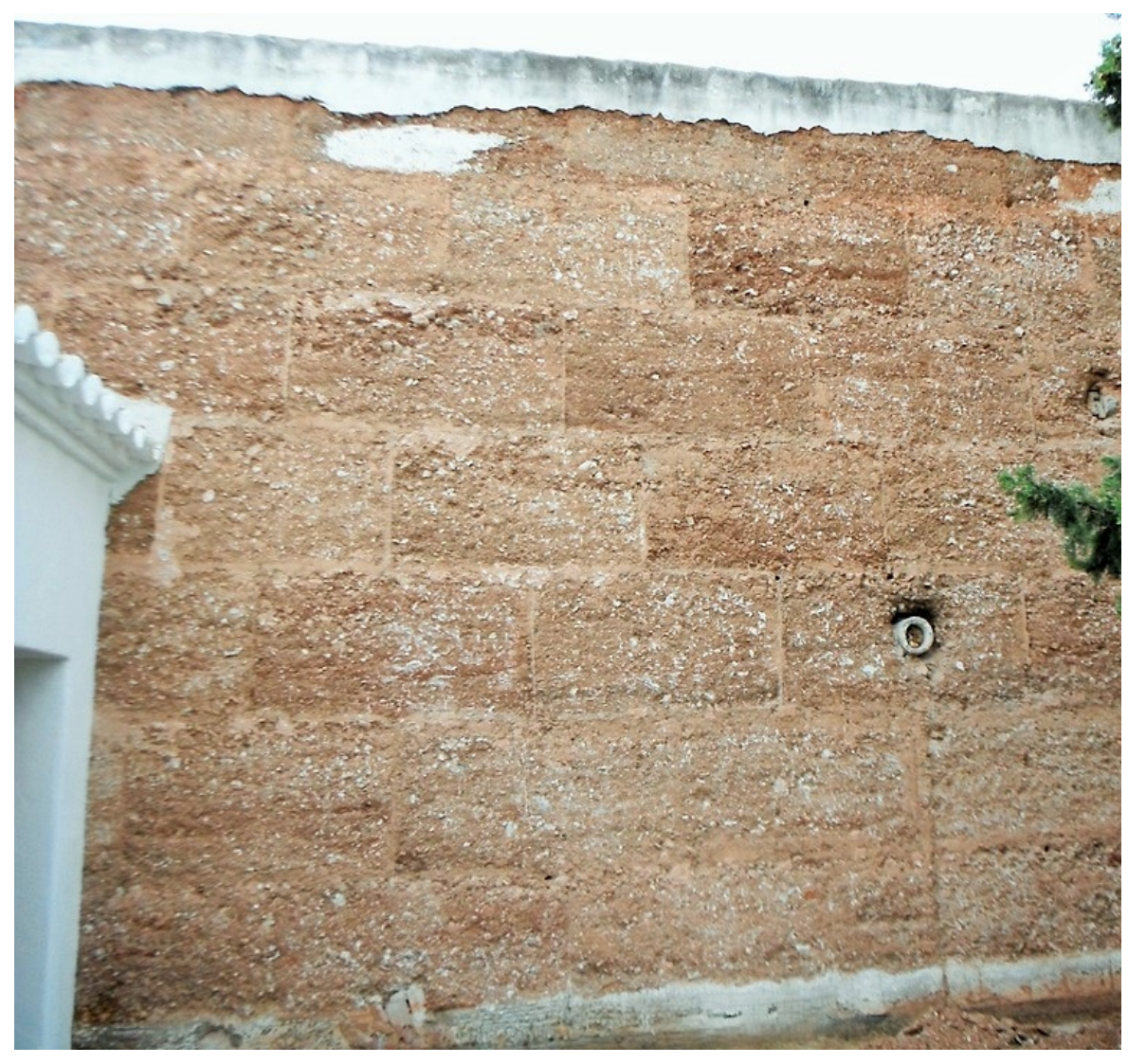

Fig. 6: Detalle del sistema constructivo de los muros del Instituto Laboral de Daimiel

caportes o en los bordes de las puertas. El instituto laboral de Daimiel es deudor del momento de su planificación y tiene importantes influencias de Jacobsen y de su fábrica de sazonar arenques en la isla de Sjaellands que Fisac conoció en su viaje europeo de $1949^{50}$.

50 CABAÑAS GALAN, M.N.: Convento dominico de Miguel Fisac en Madrid. El acento de los objetos. Tesis Doctoral. Madrid, Universidad Politécnica de Madrid. 2014, p. 381.
Fisac dio una gran importancia al entorno de sus edificios, fue muy crítico con algunos arquitectos del Movimiento Moderno por despreciar el lugar en el que construían sus edificios. El arquitecto partió de una construcción de tapial típica de la zona, pero consiguió sacarle el máximo partido plástico, cambiándole el contenido y dotándole de mejores condiciones de habitabilidad e higiene. La Mancha se convirtió en la verdadera protagonista del edificio como quedó patente en el diseño del jardín, que adquirió gran protagonismo y servía de acceso al conjunto al carecer de la típica fachada principal. En aquellos años incorporó en la mayoría de sus edificios elementos relacionados con el agua, se trataba de corrientes que circulaban y conectaban distintas partes de sus edificios. Era un recurso de influencia directa de la arquitectura hispano-árabe. En el caso del Instituto de Daimiel el origen del agua lo encontramos en una original fuente situada en el patio donde el agua manaba por la boca de un cántaro que sobresalía del muro de tapial y descargaba su caudal sobre una tinaja partida. Posteriormente circulaba hasta un estanque que recordaba a las próximas riberas del rio Guadiana. A través de estos elementos el arquitecto evocaba en sus edificios paisajes, poniendo en contacto directo la arquitectura con el lugar que la vio nacer ${ }^{51}$.

El edificio fue fríamente acogido por parte de la población local, surgieron bastantes críticas, ya que esperaban una arquitectura de corte monumentalista como era costumbre en la época. Pero, a pesar de esas pequeñas reticencias, Miguel Fisac con la construcción de este edificio se convirtió en un referente de la arquitectura educativa española. Varias décadas después debido al crecimiento del número de alumnos en la localidad se construyó un nuevo edificio derribando una de las alas del conjunto sin tener ninguna sensibilidad con el diseño original del arquitecto. El resto de la construcción quedó inutilizada, llegando a una

51 FISAC, M.: Arquitectura popular manchega. Ciudad Real, Colegio de Arquitectos, 2005, p. 15. 
situación de completo abandono y casi de ruina en los inicios de la década de los noventa. Es entonces cuando el Ayuntamiento de Daimiel decidió poner fin a este panorama iniciando un proceso de rehabilitación, que fue de gran dificultad técnica en algunas zonas como en la recuperación de las cubiertas de las aulas. En el año 1996 volvió a abrir sus puertas las dependencias restauradas del Instituto Laboral albergando en su interior las oficinas del Parque Nacional de las Tablas de Daimiel y el Centro de Interpretación del Agua y de los Humedales Manchegos que tiene entre sus objetivos principales poner en valor el recurso agua, aunque lo más paradójico del asunto es que fue imposible recuperar el cauce de agua que protagonizaba el patio central ${ }^{52}$.

\section{CONCLUSIONES}

El paso de la arquitectura de la autarquía a la segunda modernidad arquitectónica tiene como punto de partida para la mayoría de los autores el año 1949, tomando como referencia el Concurso para la Sede de los Sindicatos en el Paseo del Prado. Miguel Fisac fue protagonista en la narración de la recuperación del proceso modernizador de la arquitectura española realizada durante los años siguientes. El arquitecto se convirtió en uno de los principales precursores del debate sobre el panorama arquitectónico promovido en revistas de arquitectura y organismos oficiales. Las reflexiones producidas en estos foros fueron de especial importancia, ya que en ellas se trataron los temas más latentes del momento como la necesidad de dejar atrás el estilo clásico, la importancia de integrar la arquitectura española en el ámbito internacional o la

52 Un estudio más detallado lo encontramos en DÍAZ DEL CAMPO, R. V.: “La Protección y recuperación del patrimonio arquitectónico contemporáneo. El caso del Instituto Laboral de Daimiel" en Actas del I Congreso de Patrimonio Histórico de Castilla-La Mancha. Valdepeñas, Uned, 2007, pp. 135-146. recepción de la obra de determinados autores internacionales, entre otros. Por otro lado, Fisac fue autor de algunas obras consideradas por la historiografía como hitos dentro del proceso de renovación que se dio en nuestro país. En el Instituto Laboral de Daimiel (1951-1953), considerada por él como su primera obra moderna, se puso en práctica una nueva forma de hacer arquitectura a través de la fusión entre de la arquitectura moderna y la estética de la construcción tradicional manchega. Esta estética fue ya apuntada por su autor en el desarrollo de la $V$ Asamblea Nacional de Arquitectos: "Copiar el arte popular o clásico español conduce al folklore o a la españolada. Extraer su esencia, saber sacar esos ingredientes de verdad, de modestia, de alegría, de belleza que tiene, sería encontrar el camino de una nueva arquitectura $y$, en general, de un arte nuevo" ${ }^{\prime 53}$. El paisaje se convirtió en el verdadero protagonista del conjunto, como quedó patente en las reflexiones de la Sesión de Critica de Arquitectura dedicada a La Alhambra: "Me interesaría que se resolviera la posibilidad de que la arquitectura entrara en colaboración con el entorno agrícola por analogía o por contraste, tomando el jardín precisamente como elemento de unión" ${ }^{\prime 54}$. El arquitecto manchego gracias a una producción poliédrica y muy singular se convirtió durante aquellos años en el icono de la modernidad en nuestro país.

53 FISAC, M.: "Estética..." Op. cit., p. 13.

54 VV. AA.: "Sesión de crítica" Op. cit., p. 34. 


\section{BIBLIOGRAFÍA}

AGUILO ALONSO, M. P.: “Acerca del diseño: Miguel Fisac y el mobiliario del Consejo Superior de Investigaciones Científicas", en CABAÑAS BRAVO, M. (coord.): X Jornadas de Arte El arte español del siglo XX. Su perspectiva al final del milenio. Madrid, Consejo Superior de Investigaciones Científicas, 2001, pp. 69-88.

BERGERA, I.: "Institutos laborales: de la teoría a la práctica”, POZO, J.M. (Coord.): Los años 50: La arquitectura española y su compromiso con la historia. Pamplona, T6 Ediciones, 2002, pp. 195-207.

CABAÑAS GALÁN, M. N.: Convento dominico de Miguel Fisac en Madrid. El acento de los objetos. (Tesis Doctoral). Madrid, Universidad Politécnica de Madrid. 2014.

CALERO, A.: "Miguel Fisac: La arquitectura es un trozo de aire humanizado", Añil, n.o 14, 1998, pp. 42-46.

CAPITEL, A.: Arquitectura española años 50-años 80. Madrid, Dirección General de arquitectura, 1986.

: "Notas sobre los avatares históricos de la revista Arquitectura como medio de difusión de la innovación arquitectónica" Informes de la construcción, n.o 60, 2008, pp. 45-48.

DÍAZ SANCHEZ, J.: El triunfo del informalismo: la consideración de la pintura abstracta en la época de Franco. Madrid, Metáforas del Movimiento Moderno, 2000.

ESTEBAN, A.: “¿Modernidad o tradición? El papel de la RNA y el BDGA en el debate sobre las tendencias estilísticas de la arquitectura española",
POZO, J.M. (Coord.). Los años 50: la arquitectura española y su compromiso con la historia. Pamplona, Universidad de Navarra, 2000, pp. 241-250.

ESTEBAN MALUENDA, A.: "Tradición versus tecnología. Un debate tibio en las revistas españolas", POZO, J.M. y TRUEBA, I.(Coords.). Arquitectura, ciudad e ideología antiurbana. Pamplona, T6 Ediciones, 2002, pp. 97-106.

FERNÁNDEZ GALIANO, L.: "Instituto Laboral de Daimiel", $A \& V$

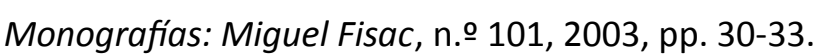

FISAC, M.: "Lo clásico y lo español", Revista Nacional de Arquitectura, n.ㅇ 78, 1948, pp. 197-198.

: "Las Tendencias Estéticas Actuales", Boletín de Dirección General de Arquitectura, n. 9, 1948, pp. 21-25.

: "Estética de la Arquitectura", Boletín de Dirección General de Arquitectura, n. 11, 1949, pp. 8-14.

: "Instituto Laboral en Daimiel", Revista Nacional de Arquitectura, n.o 139, 1953, pp. 3-14.

: "Iglesia del Colegio de Arcas Reales", Revista Nacional de Arquitectura, n.o 157, 1955, pp. 3-9.

: Arquitectura popular manchega. Ciudad Real, Colegio de Arquitectos, 2005. 
FONSECA, J.: "Tendencias actuales de la Arquitectura", Boletín de la Dirección General de Arquitectura, 11, 1949, pp. 3-5.

FULLAONDO, J. D.: Miguel Fisac. Madrid, Dirección General de Bellas Artes, 1972.

GRIJALBA, A.: "Del campo a la ciudad. Los frenéticos cincuenta", POZO, J.M. y TRUEBA, I. (Coords.). Arquitectura, ciudad e ideología antiurbana. Pamplona, T6 Ediciones, 2002, pp. 107-113.

PIZZA, A.: "Malos tiempos para la lírica. Esperanza y des-esperanza en la Europa de posguerras", POZO, J. M. (coord.): Los años 50: la arquitectura española y su compromiso con la historia. Pamplona, Universidad de Navarra, 2000, pp. 49-57.

RÁBANOS FACl, C.: "Estética de la representación en los regímenes autoritarios (el marco escenográfico arquitectónico del nazismo, fascismo y franquismo", Emblemata, n.o 12, 2006, pp. 275-288.

SAMBRICIO, C.: "De la arquitectura del nuevo estado al origen de nuestra contemporaneidad: el debate sobre la vivienda en la década de los cincuenta", Ra. Revista de arquitectura, n. 4, 2000, pp. 75-90.

SOLANA, E.: "Granada, 1953. El manifiesta de la Alhambra", Revista de Edificación RE, n.․ 17, 1994, pp. 71-73.

URRUTIA, A.: Historia de la arquitectura española. Madrid, Cátedra, 1997.

VALCÁRCEL, C. M.: "Concurso de institutos Laborales: Presentación", Revista Nacional de Arquitectura, n.o 153, 1954, p. 1.
VV. AA.: Asamblea Nacional de arquitectos los días 26, 27, 28 Y 29 de junio de 1939. Madrid, Servicios Técnicos de FET y de las JONS, Sección de Arquitectura, 1939.

ZAVALA, J.: "Tendencias actuales de la Arquitectura", Revista Nacional de Arquitectura, n. 90, 1949, p. 36. 